\title{
Diabetes-Related Health Care Utilization and Dietary Intake Among Food Pantry Clients
}

\author{
Eric M. Bomberg, 1,* Sophie Rosenmoss, ${ }^{2}$ Morgan Smith, ${ }^{3}$ Elaine Waxman, and Hilary K. Seligman ${ }^{2,3,5}$
}

\begin{abstract}
Purpose: Consuming a diet appropriate for management of diabetes mellitus (DM) is challenging, particularly for adults with food insecurity (FI). DM-related health care services are thought to support better dietary intake. In this study, we explored associations between DM-related health care utilization and dietary intake among FI adults with DM.

Methods: We used cross-sectional, baseline data (collected 2015-2016) from a trial designed to improve glycemic control among adult food pantry clients with DM. We examined intake of vegetables, fruit, sugar-sweetened beverages (SSBs), and desserts using the California Health Interview Survey dietary screener. We then examined adjusted associations between dietary intake and two components of DM-related health care utilization $(<12$ months vs. $\geq 12$ months ago): self-reported visit to a health care provider for DM management and DM selfmanagement education.

Results: Among 523 participants (mean hemoglobin A1c 9.8\%; body mass index $34.6 \mathrm{~kg} / \mathrm{m}^{2} ; 17.0 \%$ uninsured), vegetable intake was more frequent in those reporting recent utilization of health care providers for DM management and DSME-related services ( $p<0.01$ ), compared with those with less recent use. There was no association between intake frequency of fruit or SSBs and utilization of either DM-related service. Participants more recently utilizing DSME-related services consumed desserts more frequently $(p=0.02)$. Relationships persisted after controlling for DM duration, race/ethnicity, education, health insurance, location, medication adherence, and depression.

Conclusions: Among Fl patients, DM-related services offered in clinical settings may more effectively increase vegetable consumption than decrease consumption of food and beverage items that can worsen glycemic control. Food pantry settings may provide an opportunity to reinforce dietary messaging.
\end{abstract}

Keywords: diabetes mellitus; food insecurity; health care disparities; diabetes education; diet; food; nutrition

\section{Introduction}

Diabetes mellitus (DM) requires complex and multidimensional care, including diabetes education and selfmanagement of diet, physical activity, and medications. Among these complex care needs, managing diet is the most challenging for many people, and is critically im- portant for glycemic control, weight management, and comorbidity prevention. ${ }^{1}$ To support individuals with $\mathrm{DM}$ in consuming diets appropriate for glycemic management, both the American Diabetes Association (ADA) and the Centers for Disease Control and Prevention recommend that all patients actively engage

\footnotetext{
1Department of Pediatrics, Division of Endocrinology and the Center for Pediatric Obesity Medicine, University of Minnesota, Minneapolis, Minnesota.

${ }^{2}$ Center for Vulnerable Populations at Zuckerberg San Francisco General Hospital, San Francisco, California.

${ }^{3}$ Feeding America, Chicago, Illinois.

${ }^{4}$ Urban Institute, Washington, District of Columbia.

${ }^{5}$ Department of Medicine, Division of General Internal Medicine, University of California, San Francisco, California.
}

*Address correspondence to: Eric M. Bomberg, MD, MAS, Department of Pediatrics, Division of Endocrinology and the Center for Pediatric Obesity Medicine, 717 Delaware Street SE, Room 371, Minneapolis, MN 55414, E-mail: bombe002@umn.edu

(c) Eric M. Bomberg et al. 2019; Published by Mary Ann Liebert, Inc. This Open Access article is distributed under the terms of the Creative Commons License (http://creativecommons.org/licenses/by/4.0), which permits unrestricted use, distribution, and reproduction in any medium, provided the original work is properly cited. 
with a health care team in self-management and treatment planning. ${ }^{2,3}$ As part of diabetes mellitus selfmanagement education (DMSE), individuals with $\mathrm{DM}$ are encouraged to limit consumption of sugarsweetened beverages (SSBs); limit foods with added sugar; and focus carbohydrate intake on healthier choices, including vegetables, fruit, and whole grains. Such dietary changes improve insulin sensitivity, glycemic control, and lipid profiles. ${ }^{4,5}$

While achieving these dietary changes can be difficult for all patients, food insecurity (FI) intensifies the challenges. ${ }^{6}$ FI refers to "limited or uncertain access to nutritionally adequate and safe food required for an active, healthy life." ${ }^{7}$ About 37 million people in the United States live in food insecure households. ${ }^{8}$

For individuals with both FI and DM, coping strategies such as shifting dietary intake toward cheaper and more obesogenic foods and putting off medication purchases or clinic visits to pay for food may increase food access, but can worsen glycemic control. ${ }^{9,10}$ Food pantries and other emergency food services (e.g., soup kitchens) can also increase food access, ${ }^{11,12}$ but food available in these settings may be limited in variety, calorically dense, and/or poor in nutritional quality. ${ }^{13,14}$ Given the added burden FI places on DM selfmanagement, individuals with both DM and FI may benefit from more intense support from health care providers and allied health professionals. ${ }^{15,16}$

Few studies have examined the relationship between utilization of DM-related health care services and dietary intake in the general population, and this relationship is particularly poorly understood among FI populations. Therefore, we sought to determine the extent to which utilization of health care provider services for DM and/or DSME is associated with improved dietary intake among adults with DM-seeking assistance at food pantries. We hypothesized that food pantry clients with DM more recently utilizing DM-related health care would report healthier dietary intake, including increased frequency of vegetables and fruit and reduced frequency of added sugar intake, compared with those with less recent or no utilization of DM-related health care services.

\section{Methods}

Setting and sample

This is a cross-sectional study using baseline data (collected from October 2015 to September 2016) from the Feeding America Intervention Trial for Health-Diabetes Mellitus (FAITH-DM) study. The design, methods, pop- ulation, and results of FAITH-DM (NCT02569060) have previously been published. ${ }^{17}$ The research protocol for FAITH-DM was approved by the Western institutional review board with additional review (for data analysis only) by the University of California San Francisco and Urban Institute institutional review boards. ${ }^{17}$ All participants provided written informed consent before participation.

In brief, FAITH-DM was a 6-month randomized, waitlist-controlled trial performed at 27 food pantries affiliated with three food banks (Alameda County Community Food Bank, Oakland, CA; Gleaners Community Food Bank of Southeastern Michigan, Detroit, MI; and Houston Food Bank, Houston, TX). A waitlist control trial involves a group of participants first being assigned to a waiting list and then receiving intervention after the active treatment group, and can be performed when it may be unethical to deny participants access to treatment. ${ }^{18} \mathrm{~A}$ total of 568 individuals with DM participated in an intervention consisting of self-management support provided at the food pantry and provision of diabetesappropriate food boxes every 2 weeks. The primary outcome was hemoglobin Alc (HbAlc).

Inclusion criteria were age $\geq 18$ years; an onsite point-of-care (POC) HbAlc $\geq 7.5 \%$; existing or new food pantry client; fluency in English and/or Spanish; a reliable mode of contact; and intention to remain in the study area for $\geq 12$ months. Exclusion criteria included cognitive impairment, pregnancy or $<6$ weeks postpartum, and/or history of type $1 \mathrm{DM}$. For this analysis of baseline data, we considered all participants to have FI under the assumption that food pantry clients are currently, recently, or at high risk of FI. Indeed, studies have shown that most food pantry users report having FI. ${ }^{11,12}$ We excluded participants not diagnosed with DM until the day of trial enrollment, as these individuals would not have previously been subject to guidelines recommending DM-related health care utilization. In addition, we excluded participants not responding to survey items related to DM-related health care utilization.

\section{Measures}

All measures for this secondary analysis were selected $a$ priori based upon our hypothesis that food pantry clients with DM more recently utilizing DM-related health care would report healthier dietary intake frequency. We defined DM-related health care utilization as (1) visits with a medical provider (doctor or other health care professional) for DM management and/or (2) use of DSME-related services. All participants were 
first asked, "Is there one doctor or other health professional that you usually see for your diabetes? Do not include diabetes educators, dieticians, or foot and eye doctors." To assess the last time a participant saw this provider, those who responded positively to this question were then asked, "When was the last time you saw this doctor or other health professional for your diabetes" (<3 months; 3-6 months; 6-12 months; >12 months; never; don't know; refused).

To assess the last time a participant used DSMErelated services, all participants, including those responding negatively to having a medical provider for DM management, were asked, "When was the last time you saw a diabetes nurse educator or dietician or nutritionist for your diabetes? Do not include doctors or other health professionals" ( $<3$ months; 3-6 month; 6-12 months; >12 months; never; don't know; refused).

We dichotomized DM-related health care utilization (visit with a medical provider for DM management and use of DSME-related services) into more recent utilization (within the last 12 months) and less recent utilization (>12 months ago or never). ADA recommendations for how often an adult with DM should visit a health care provider are individualized according to glycemic control and other factors. ${ }^{19}$ For DMSE, the recommended frequency is "at least annually." We therefore dichotomized both utilization variables at 12 months for consistency, and performed sensitivity analyses examining the impact of dichotomizing the utilization variables at other cut-points: (1) within the last 6 months versus $>6$ months ago or never, and (2) any versus no reported utilization.

Our dietary intake variables included self-reported frequency of vegetables (green leafy lettuce or salad and/or other vegetables), fruit, SSBs (regular soda, fruit-flavored drinks, and 100\% fruit juice), and desserts (baked and/or frozen). We did not include beans and potatoes with vegetable intake because these items contain higher carbohydrate loads and, in the case of potatoes, are high glycemic index; and the ADA emphasizes low-carbohydrate vegetables. ${ }^{1,20}$ Further, we considered $100 \%$ fruit juice as a SSB because the sugar content of these beverages may be similar to or higher than other SSBs. ${ }^{21}$

All dietary intake items were derived from the 2005 California Health Interview Survey (CHIS) dietary screener, a 10-item food frequency questionnaire that asks participants about food and beverage intake over the past month. ${ }^{22}$ We selected the above items from the CHIS dietary screener $a$ priori because of our interest in specifically examining associations between health care utilization and intake of low-carbohydrate (nonstarchy) vegetables, fruit, and foods and beverages classically containing significant amounts of added sugar. All responses (times per day, week, or month) were converted into daily intake frequencies.

POC $\mathrm{HbAlc}$ testing was performed by trained food bank staff and volunteers. All other measures were obtained from the FAITH-DM baseline survey. Demographic characteristics included age, gender, self-reported height and weight (used to calculate body mass index), race/ethnicity (Caucasian/White, Black/African American, Hispanic/Latino, Native American, Asian or Pacific Islander, and Multi-racial), education level (some high school or less; high school graduate, General Education Development degree, some college, Associate of Arts, or technical school; college graduate and/or graduate degree), and presence of health insurance (including through current/former employer or union, purchased directly from insurance company, Medicare, Medicaid, Medical Assistance, Children's Health Insurance Program, TRICARE, Indian Health Services, and other).

We assessed medication nonadherence using four previously developed yes/no items: forgetting to take medications ever, not careful about taking medications at times, stopping taking medications when feeling better, and stopping taking medications if feel worse while taking them. Zero affirmatives to these questions represented the lowest level of nonadherence (highest adherence), and four affirmatives represented the highest level of nonadherence. Depressive symptoms were assessed using the Patient Health Questionnaire-8 (PHQ-8) scored from 0 to 24 , with a score of $0-4$ representing minimal depressive, 5-9 mild depressive, 10-14 moderate depressive, 15-19 moderately severe depressive, and 20-24 severe depressive symptoms per standard scoring procedures. ${ }^{23}$

\section{Data analysis}

Data are reported as means with standard errors for continuous variables and as numbers with percentages for categorical variables. We compared sociodemographic characteristics of participants reporting more versus less recent DM-related health care utilization using $t$-tests for continuous and $\chi^{2}$ tests for categorical variables. We used $t$-tests to determine unadjusted associations between recentness of DM-related health care utilization and dietary intake frequencies, followed by multiple linear regression to examine these associations after adjusting for DM duration, race/ethnicity, education level, health insurance, medication adherence, PHQ-8 score, and food bank location. In these regression 
analyses, the model covariates were categorized as described above, and all covariates added to the regression models were selected given their potential role as confounders. ${ }^{24-31}$

Missing data for dietary intake items were $<1 \%$ and for the model covariates, $<2.5 \%$. Statistical significance was based on a type I error rate of 0.05 . Model fit was assessed by plotting residual versus fitted plots to assess for homoscedasticity. All statistical analyses were conducted using Stata 14.1 (StataCorp, College Station, TX).

\section{Results}

\section{Sociodemographic characteristics}

The data analysis included 523 of the 562 available participants $(6.6 \%$ excluded because they were not diagnosed with DM until the day of survey administration; two participants excluded because they did not respond to DM-related health care utilization questions). Participants were predominantly female $(68.0 \%)$, had a mean age of 54.8 years, and a mean PHQ-8 score consistent with mild depression $(8.1 \pm 0.3)$. About $50 \%$ of participants reported consulting a medical provider for DM management and 30\% reported utilizing DSME-related services within the last 12 months.

Sociodemographic characteristics comparing participants with more and less recent DM-related health care utilization are summarized in Table 1 . Those reporting more recent DM-related health care utilization had a longer DM duration and a lower HbAlc compared with those reporting less recent use. Participants with insurance were less likely to have spent $>12$ months without seeing a medical provider for DM $(p<0.01)$, but were not less likely to have received DSME-related services.

In sensitivity analyses (Supplementary Tables S1 and S2), similar results were observed when DM-related health care utilization was dichotomized at 6 months, and at ever (vs. never) except for the following: (1) DM duration, PHQ-8 scores, and education level were not statistically significantly different between groups when visits with a medical provider for DM management were dichotomized at 6 months; and (2) DM duration was not statistically significantly different between groups when DSME-related service use was dichotomized at 6 months.

Table 1. Baseline Characteristics of Food Pantry Clients with Diabetes Mellitus Comparing More to Less Recent Diabetes Mellitus-Related Health Care Exposure

\begin{tabular}{|c|c|c|c|c|c|c|c|}
\hline & \multirow[b]{2}{*}{ Total $(n=523)$} & \multicolumn{3}{|c|}{ DM medical provider exposure } & \multicolumn{3}{|c|}{ DSME-related services exposure } \\
\hline & & $\begin{array}{c}>12 \text { months } \\
\text { ago/never } \\
(n=255)\end{array}$ & $\begin{array}{l}\text { Within the } \\
\text { last } 12 \text { months } \\
(n=268)\end{array}$ & $p^{\mathrm{a}}$ & $\begin{array}{c}>12 \text { months } \\
\text { ago/never } \\
(n=364)\end{array}$ & $\begin{array}{l}\text { Within the } \\
\text { last } 12 \text { months } \\
(n=159)\end{array}$ & $p^{\mathrm{a}}$ \\
\hline Gender (\% female) & 355 (68.0\%) & 179 (70.2\%) & $176(65.9 \%)$ & 0.30 & $253(69.7 \%)$ & $102(64.2 \%)$ & 0.21 \\
\hline Age $($ mean $\pm S E)$ & $54.8 \pm 0.5$ & $53.4 \pm 0.7$ & $56.1 \pm 0.6$ & $<0.01$ & $55.1 \pm 0.6$ & $54.1 \pm 0.8$ & 0.34 \\
\hline Diabetes duration (years; mean \pm SE) & $12.9 \pm 0.5$ & $11.9 \pm 0.7$ & $13.9 \pm 0.7$ & 0.04 & $12.2 \pm 0.6$ & $14.5 \pm 1.0$ & 0.04 \\
\hline Body mass index (mean $\pm \mathrm{SE})$ & $34.6 \pm 0.4$ & $34.4 \pm 0.6$ & $34.7 \pm 0.5$ & 0.73 & $34.7 \pm 0.5$ & $34.3 \pm 0.7$ & 0.58 \\
\hline A1c (\%; mean \pm SE) & $9.8 \pm 0.1$ & $10.0 \pm 0.1$ & $9.5 \pm 0.1$ & $<0.01$ & $9.9 \pm 0.1$ & $9.5 \pm 0.1$ & 0.04 \\
\hline Medication nonadherence score (mean $\pm \mathrm{SE}$ ) & $1.14 \pm 0.1$ & $1.10 \pm 0.1$ & $1.17 \pm 0.1$ & 0.47 & $1.09 \pm 0.1$ & $1.23 \pm 0.1$ & 0.24 \\
\hline Depression (PHQ-8; mean $\pm \mathrm{SE})$ & $8.1 \pm 0.3$ & $8.7 \pm 0.4$ & $7.6 \pm 0.4$ & 0.04 & $8.2 \pm 0.3$ & $8.0 \pm 0.5$ & 0.77 \\
\hline \multicolumn{8}{|l|}{ Food bank location } \\
\hline Detroit & 175 (33.5\%) & $127(49.8 \%)$ & $48(17.9 \%)$ & $<0.01$ & 145 (39.8\%) & $30(18.9 \%)$ & $<0.01$ \\
\hline Houston & $240(45.9 \%)$ & 79 (31.0\%) & $161(60.1 \%)$ & & $156(42.9 \%)$ & $84(52.8 \%)$ & \\
\hline Oakland & $108(20.7 \%)$ & $49(19.2 \%)$ & $59(22.0 \%)$ & & $63(17.3 \%)$ & $45(28.3 \%)$ & \\
\hline \multicolumn{8}{|l|}{ Race/ethnicity } \\
\hline Caucasian/White & $69(13.2 \%)$ & $38(14.9 \%)$ & $31(11.6 \%)$ & 0.27 & $57(15.7 \%)$ & $12(7.6 \%)$ & 0.05 \\
\hline Black/African American & 176 (33.7\%) & $92(36.1 \%)$ & $84(31.3 \%)$ & & $123(33.8 \%)$ & $53(33.3 \%)$ & \\
\hline Latino/Hispanic & $262(50.1 \%)$ & $119(46.7 \%)$ & $143(53.4 \%)$ & & $172(47.3 \%)$ & 90 (56.6\%) & \\
\hline Other $^{\mathrm{b}}$ & $16(3.1 \%)$ & $6(2.4 \%)$ & $10(3.7 \%)$ & & $12(3.3 \%)$ & $4(2.5 \%)$ & \\
\hline \multicolumn{8}{|l|}{ Education } \\
\hline Some high school or less & $241(46.2 \%)$ & 112 (43.9\%) & $129(48.3 \%)$ & 0.04 & $164(45.1 \%)$ & 77 (48.7\%) & 0.43 \\
\hline HS Grad/GED/some college/AA/Tech & 242 (46.4\%) & $130(51.0 \%)$ & $112(42.0 \%)$ & & $175(48.1 \%)$ & 67 (42.4\%) & \\
\hline College grad/grad degree & $39(7.5 \%)$ & $13(5.1 \%)$ & $26(9.7 \%)$ & & $25(6.9 \%)$ & $14(8.9 \%)$ & \\
\hline Uninsured $(\%)^{c}$ & $87(17.0 \%)$ & $54(21.6 \%)$ & $33(12.6 \%)$ & $<0.01$ & $62(17.4 \%)$ & $25(15.9 \%)$ & 0.68 \\
\hline
\end{tabular}

${ }^{a} t$-Test except race/ethnicity and education $\left(\chi^{2}\right)$.

${ }^{b}$ Includes Native American, Asian or Pacific Islander, multiracial, and other.

Including insurance through current/former employer or union, purchased directly from insurance company, Medicare, Medicaid, Medical Assistance, Children's Health Insurance Program, TRICARE, Indian Health Services, and other.

AA, Associate of Arts; DM, diabetes mellitus; DSME, diabetes self-management education; GED, general education development; HS, high school; PHQ-8, Patient Health Questionnaire-8 (depression screener); SE, standard error. 
Table 2. Associations Between Diabetes Mellitus Health Care Visits and Dietary Consumption Frequency Among Food Pantry Clients with Diabetes Mellitus

\begin{tabular}{|c|c|c|c|c|c|c|}
\hline & \multicolumn{3}{|c|}{$\begin{array}{l}\text { Dietary consumption } \\
\text { frequency-unadjusted (times/day) }\end{array}$} & \multicolumn{3}{|c|}{$\begin{array}{l}\text { Dietary consumption } \\
\text { frequency-adjusted (times/day) }\end{array}$} \\
\hline & $\begin{array}{l}>12 \text { months } \\
\text { ago/never }\end{array}$ & $\begin{array}{l}\text { Within the last } \\
12 \text { months }\end{array}$ & $p$ & $\begin{array}{l}>12 \text { months } \\
\text { ago/never }\end{array}$ & $\begin{array}{l}\text { Within the last } \\
12 \text { months }\end{array}$ & $p$ \\
\hline \multicolumn{7}{|l|}{ DM medical provider exposure } \\
\hline $\begin{array}{l}\text { Sugar-sweetened beverages } \\
(\text { mean } \pm S E)^{b}\end{array}$ & $0.80 \pm 0.06$ & $0.68 \pm 0.06$ & 0.18 & $0.76 \pm 0.07$ & $0.69 \pm 0.07$ & 0.53 \\
\hline Desserts (mean $\pm \mathrm{SE})^{\mathrm{c}}$ & $0.33 \pm 0.03$ & $0.34 \pm 0.03$ & 0.70 & $0.31 \pm 0.04$ & $0.38 \pm 0.03$ & 0.25 \\
\hline Vegetables $(\text { mean } \pm S E)^{d}$ & $0.89 \pm 0.06$ & $1.21 \pm 0.06$ & $<0.01$ & $0.90 \pm 0.07$ & $1.22 \pm 0.07$ & $<0.01$ \\
\hline Fruit (mean $\pm \mathrm{SE})$ & $0.74 \pm 0.78$ & $0.83 \pm 0.73$ & 0.16 & $0.73 \pm 0.05$ & $0.86 \pm 0.05$ & 0.08 \\
\hline \multicolumn{7}{|l|}{ DSME-related services exposure } \\
\hline $\begin{array}{l}\text { Sugar-sweetened beverages } \\
(\text { mean } \pm S E)^{a}\end{array}$ & $0.70 \pm 0.04$ & $0.82 \pm 0.10$ & 0.20 & $0.67 \pm 0.06$ & $0.84 \pm 0.09$ & 0.10 \\
\hline Desserts $(\text { mean } \pm \mathrm{SE})^{\mathrm{b}}$ & $0.30 \pm 0.02$ & $0.41 \pm 0.05$ & 0.02 & $0.31 \pm 0.03$ & $0.43 \pm 0.04$ & 0.03 \\
\hline Vegetables $(\text { mean } \pm S E)^{c}$ & $0.97 \pm 0.05$ & $1.24 \pm 0.09$ & $<0.01$ & $1.00 \pm 0.06$ & $1.24 \pm 0.09$ & 0.02 \\
\hline Fruit (mean $\pm S E)$ & $0.76 \pm 0.04$ & $0.84 \pm 0.06$ & 0.27 & $0.79 \pm 0.04$ & $0.81 \pm 0.06$ & 0.81 \\
\hline
\end{tabular}

${ }^{a}$ Adjusted for duration of diabetes, race/ethnicity, education, health insurance status, study site, and medication adherence, and depression (PHQ-8).

Includes nondiet soda, nondiet flavored drinks, and 100\% fruit juice.

Includes baked and frozen desserts.

dIncludes greens and other vegetables.

\section{Dietary intake}

Associations between DM-related health care utilization and dietary intake frequency are summarized in Table 2. In the unadjusted analyses, vegetable consumption frequency was greater in those reporting more recent utilization of medical providers for DM management (1.2 times/day vs. 0.9 times/day; $p<0.01)$ and DSME-related services (1.2 times/day vs. 1.0 times/day; $p<0.01)$ compared with those reporting less recent use. There was no difference between those with more or less recent utilization of either DM-related health care service in fruit or SSB consumption frequency. Participants more recently utilizing DSME-related services consumed desserts more frequently compared with those with less recent use $(p=0.02)$. After adjusting for DM duration, race/ethnicity, education level, health insurance status, medication adherence, PHQ-8 score, and food bank location, all of the statistically significant associations between DM-related health care utilizations and dietary consumption frequencies observed in the unadjusted analyses persisted.

In sensitivity analyses (Supplementary Table S3), similar results were obtained when DM-related health care utilizations were dichotomized at 6 months and by ever (vs. never) utilizing these services, except for the following: (1) fruit consumption frequency was greater in those reporting ever (vs. never) receiving DSME-related services (0.9 times/day vs. 0.7 times/ day; $p=0.02$ ) in unadjusted analysis, (2) vegetable consumption frequency was not statistically significantly between those receiving DSME-related services within the last 6 months versus $>6$ months ago in adjusted analysis, and (3) dessert consumption was not statistically significantly different between those receiving DSME-related services more or less recently for both sensitivity analyses.

\section{Discussion}

In this study of U.S. food pantry clients with DM, more recent utilization of a medical provider for DM management and/or DSME-related services were both associated with increased vegetable consumption frequency. However, intake frequency of SSB and desserts was not associated with utilization of either DM-related health care service. These relationships persisted after controlling for sociodemographic characteristics, and largely persisted in sensitivity analyses, suggesting the robustness of these findings.

There are several possibilities to consider for why recent DM-related health care utilization was associated with increased vegetable consumption frequency. It may be that use of DM-related services motivates an individual to increase dietary consumption of healthy foods such as vegetables. This hypothesis is consistent with the theory of change underlying most DM-related services. Indeed, studies have shown that DSME is associated with improved DM knowledge, self-care behaviors, and increased likelihood of following best practice treatment recommendations. ${ }^{32-36}$ Given the cross-sectional nature of this study however, it is also possible that individuals consuming vegetables more often seek DM care, or have fewer barriers to accessing 
DM-related health care services. The finding that participants who reported seeing a medical provider for DM management were also more likely to be insured supports this theory.

Contrary to our hypothesis, those more recently utilizing DM-related health care services did not report decreased SSB or dessert intake frequency. There are several potential explanations for this finding. First, the impact that DM-related health care services have on added sugar consumption has not been well studied and is therefore unclear, despite being one of the primary intended goals of DSME. While DSME is associated with improved DM-related outcomes, ${ }^{1}$ it is possible that such interventions have more impact on improving other DM-related lifestyle modifications (e.g., increasing medication compliance, promoting physical activity) and less effect on added sugar intake itself.

Second, the food environment may overwhelm nutritional messaging originating in the clinical setting. Food pantries are predominantly situated in low-income neighborhoods and cater to low-income clients. ${ }^{12}$ Lowincome neighborhoods have a higher prevalence of fast food restaurants and convenience stores (so called "food swamps") compared with high-income areas. ${ }^{37}$ In addition, although the charitable feeding system has dramatically increased the nutrient content of available food recently, ${ }^{38,39}$ it was originally designed for the distribution of shelf-stable food donations that are generally calorically dense and poorer in nutritional quality. Chronic exposure to poorer dietary options may contribute to dietary choices. Indeed, environmental cues for sugar consumption in low-income neighborhoods and/or in food pantries, where these cues may be more pervasive ${ }^{40}$ and healthier dietary options less available, ${ }^{39}$ may supersede messaging from the health care setting to avoid these unhealthy options.

Third, it is possible that messaging from traditional health care settings to avoid added sugar is overall less successful than messaging to increase intake of healthier dietary options. In particular, in the case of FI it may be that the appeal of calorically dense foods makes countermessaging more difficult, as substitutions for these foods with healthier alternatives are often cost prohibitive. ${ }^{41}$

Strengths of this study include a large multiethnic cohort with participants from three food banks representing different demographic locations across the United States. However, our results must be interpreted within the context of a number of limitations. As this is a cross-sectional study, we cannot be certain that utilization of DM-related health care services is causally related to dietary intake. The CHIS dietary screener does not allow for direct determination of portion sizes, and self-reported measures of health care utilization were not objectively verified. Further, the CHIS dietary screener does not specifically ask about intake of presweetened teas, sports drinks, and energy drinks, which may also impact glycemic control similar to other SSBs. Thus, our findings should be considered preliminary, and future studies including additional measures of intake, such as food diaries and 24-h dietary recalls, are needed for validation. ${ }^{42}$

Moreover, our results may not be generalizable outside of the food pantry setting or to individuals with type $1 \mathrm{DM}$. Finally, nutritional knowledge was not specifically assessed. While the overall association between nutritional knowledge and dietary intake is only weakly positive, ${ }^{43}$ it is possible that dietary knowledge plays a more influential role in the decision to consume a healthier diet than the encounter with a DM health care provider itself. Further studies should explore the role that nutritional knowledge has in mediating the relationship between DM-related health care utilization and dietary intake, including among those with FI.

\section{Conclusions}

Among food pantry users, more recent utilization of DMrelated health care was associated with increased vegetable consumption frequency, but not with decreased SSB or dessert consumption frequency. Among highly vulnerable patients, DM-related services traditionally offered in the clinical setting may be more effective at increasing consumption of healthier items such as vegetables than decreasing the consumption of less healthy items that can worsen glycemic control. The food pantry setting may, therefore, provide an additional opportunity to reinforce healthy dietary intake messaging.

\section{Author Disclosure Statement}

No competing financial interests exist.

\section{Funding Information}

The analysis reported in this publication was supported by the National Institute of Diabetes and Digestive and Kidney Diseases (NIDDK) of the National Institutes of Health under Award Numbers 2T32DK007161-42, 2T32DK007418-36A1, and P30DK092924. The parent study (FAITH-DM) was supported by Feeding America, the Laura and John Arnold Foundation, the Urban Institute through a Robert Wood Johnson Foundation grant, NIDDK under award 
P30DK092924, and Centers for Disease Control and Prevention under award 3U48DP004998-01S1. The content is solely the responsibility of the authors and does not necessarily represent the official views of the National Institutes of Health or Centers for Disease Control and Prevention.

\section{Supplementary Material} Supplementary Table S1 Supplementary Table S2 Supplementary Table S3

\section{References}

1. American Diabetes Association. 5. Lifestyle management: standards of medical care in diabetes-2019. Diabetes Care. 2019;42(Suppl 1):S46S60.

2. Powers MA, Bardsley J, Cypress M, et al. Diabetes self-management education and support in type 2 diabetes: a joint position statement of the American Diabetes Association, the American Association of Diabetes Educators, and the Academy of Nutrition and Dietetics. Diabetes Care. 2015;38:1372-1382.

3. Centers for Disease Control and Prevention. Diabetes: Education and Support. Available at www.cdc.gov/diabetes/managing/education.html Accessed October 19, 2019.

4. Malik VS, Popkin BM, Bray GA, et al. Sugar sweetened beverages, type 2 diabetes and cardiovascular disease risk. Circulation. 2010;121:1356-1364.

5. Sarmento RA, Antonio JP, Lamas de Miranda I, et al. Eating patterns and health outcomes in patients with type 2 diabetes. J Endocr Soc. 2017;2: $42-52$

6. Seligman HK, Schillinger D. Hunger and socioeconomic disparities in chronic disease. N Engl J Med. 2010;363:6-9.

7. United States Department of Agriculture Economic Research Service. Food insecurity in the U.S. Available at www.ers.usda.gov/topics/foodnutrition-assistance food-security-in-the-us/key-statistics-graphics.aspx Accessed October 18, 2019.

8. Coleman-Jensen A, Rabbitt MP, Gregory CA, et al. Household Food Security in the United States in 2017, ERR-256. U.S. Department of Agriculture, Economic Research Service. Available at www.ers.usda.gov/ webdocs/publications/85215/tb-1945.pdf?v=0 Accessed August 28, 2019.

9. Seligman HK, Bindman AB, Vittinghoff $E$, et al. Food insecurity is associated with diabetes mellitus: results from the National Health Examination and Nutrition Examination Survey (NHANES) 1999-2002. J Gen Intern Med. 2007;22:1018-1023.

10. Mayer VL, McDonough K, Seligman H, et al. Food insecurity, coping strategies and glucose control in low-income patients with diabetes. Public Health Nutr. 2016;19:1103-1111.

11. O'Connell KE, Holben DH, Holcomb JP. Use of food pantries is associated with household food insecurity in Ohio. J Hunger Environ Nutr. 2008;2: 93-109.

12. Weinfield NS, Mills G, Borger C, et al.; for Feeding America. Hunger in America 2014 National Report. Available at help.feedingamerica.org/ HungerInAmerica/hunger-in-america-2014-full-report.pdf Accessed October 18, 2019.

13. Tse $C$, Tarasuk V. Nutritional assessment of charitable meal programmes serving homeless people in Toronto. Public Health Nutr. 2008;11:12961305.

14. Akobundu UO, Cohen NL, Laus MJ, et al. Vitamins A and C, calcium, fruit and dairy products are limited in food pantries. J Am Diet Assoc. 2004; 104:811-813.

15. Lyles $C R$, Wolf $M S$, Schillinger $D$, et al. Food insecurity in relation to changes in hemoglobin A1c, self-efficacy, and fruit/vegetable intake during a diabetes educational intervention. Diabetes Care. 2013;36:14481453.

16. Seligman HK, Berkowitz SA. Aligning programs and policies to support food security and public health goals in the United States. Annu Rev Public Health. 2018;11:1-19.
17. Seligman HK, Smith M, Rosenmoss $S$, et al. Comprehensive diabetes selfmanagement support from food banks: a randomized controlled trial. Am J Public Health. 2018;108:1227-1234.

18. Elliott SA, Brown JS. What are we doing to waiting list controls? Behav Res Ther. 2002;40:1047-1052.

19. American Diabetes Association. 6. Glycemic targets: standards of medical care in diabetes-2019. Diabetes Care. 2019;42(Suppl 1):S61-S70.

20. Bowen ME, Cavanaugh KL, Wolff K, et al. The Diabetes Nutrition Education Study randomized controlled trial: a comparative effectiveness study of approaches to nutrition in diabetes self-management education. Patient Educ Couns. 2016;99:1368-1376.

21. Walker RW, Dumke KA, Goran MI. Fructose content in popular beverages made with and without high-fructose corn syrup. Nutrition. 2014;30:928935.

22. UCLA Center for Health Policy Research, California Department of Health Services, Public Health Institute. CHIS 2005 Adult Questionnaire. Version 6.4. Regents of the University of California. 2010. Available at https:// healthpolicy.ucla.edu/chis design/Documents/CHIS2005_method1.pdf Accessed October 19, 2019.

23. Kroenke K, Strine TW, Spitzer RL, et al. The PHQ-8 as a measure of current depression in the general population. J Affect Disord. 2009;114:163-173.

24. Taylor YJ, Spencer MD, Mahabaleshwarker R, et al. Racial/ethnic differences in healthcare use among patients with uncontrolled and controlled diabetes. Ethn Health. 2017;10:1-12.

25. Lee $\mathrm{Y}, \mathrm{Kim} \mathrm{RB}$, Lee $\mathrm{HJ}$, et al. Relationships among medication adherence, lifestyle modification, and health-related quality of life in patients with acute myocardial infarction: a cross-sectional study. Health Qual Life Outcomes. 2018;16:1-8

26. Kang $\mathrm{H}$, Lobob JM, Kim S, et al. Cost-related medication non-adherence among U.S. adults with diabetes. Diabetes Res Clin Pract. 2018;143:24-33.

27. Ko S, Park S, Cho J, et al. Influence of the duration of diabetes on the outcome of a diabetes self-management education program. Diabetes Metab J. 2012;36:222-229.

28. Zimmerman EB, Woolf SH. Understanding the relationship between education and health: discussion paper. Institute of Medicine, Washington DC. Available at https://nam.edu/wp-content/uploads/2015/06/BPH UnderstandingTheRelationship1.pdf Accessed October 18, 2019.

29. Smith DA, Akira A, Hudson K, et al. The effect of health insurance coverage and the doctor-patient relationship on health care utilization in high poverty neighborhoods. Prev Med Rep. 2017;7:158-161.

30. Palinkas A, Sandor J, Papp M, et al. Associations between untreated depression and secondary health care utilization in patients with hypertension and/or diabetes. Soc Psychiatry Psychiatr Epidemiol. 2019;54: 255-276.

31. Paans NPG, Gibson-Smith D, Bota M, et al. Depression and eating styles are independently associated with dietary intake. Appetite. 2019;134: 103-110.

32. Haas L, Maryniuk M, Beck J, et al. 2012 Standards Revision Task Force. National standards for diabetes self-management education and support Diabetes Care. 2014;37(Suppl. 1):S144-S153.

33. Chrvala CA, Sherr D, Lipman RD. Diabetes self management education for adults with type 2 diabetes mellitus: a systematic review of the effect on glycemic control. Patient Educ Couns. 2016;99:926-943.

34. He X, Li J, Wang B, et al. Diabetes self management education reduces risk of all-cause mortality in type 2 diabetes patients: a systematic review and meta-analysis. Endocrine. 2017;55:712-731.

35. Duncan I, Ahmed T, Li QE, et al. Assessing the value of the diabetes educator. Diabetes Educ. 2011;37:638-657.

36. Duncan I, Birkmeyer C, Coughlin S, et al. Assessing the value of diabetes education. Diabetes Educ. 2009;35:752-760.

37. Hilmers A, Hilmers DC, Dave J. Neighborhood disparities in access to healthy foods and their effects on environmental justice. Am J Public Health. 2012;102:1644-1654.

38. Campbell EC, Ross M, Webb KL. Improving the nutritional quality of emergency food: a study of food bank organizational culture, capacity, and practices. J Hunger Environ Nutr. 2013;8:261-280.

39. Ross M, Campbell EC, Webb KL. Recent trends in the nutritional quality of food banks' food and beverage inventory: case studies of six California food banks. J Hunger Environ Nutr. 2013;8:294-309.

40. Cassady DL, Liaw K, Soederberg Miller LM. Disparities in obesity-related outdoor advertising by neighborhood income and race. J Urban Health 2015;92:835-842. 
41. Darmon N, Drewnowski A. Contribution of food prices and diet cost to socioeconomic disparities in diet quality and health: a systematic review and analysis. Nutr Rev. 2015;73:643-660.

42. Taylor RM, Haslam RL, Burrows TL. Issues in measuring and interpreting diet and its contribution to obesity. Curr Obes Rep. 2019;8:53-65.

43. Spronk I, Kullen C, Burdon C, et al. Systematic review: relationship between nutrition knowledge and dietary intake. Br J Nutr. 2014;111:17131726 .

Cite this article as: Bomberg $E M$, Rosenmoss $S$, Smith $M$, Waxman $E$ Seligman HK (2019) Diabetes-related health care utilization and dietary intake among food pantry clients, Health Equity 3:1, 644-651, DOI: 10.1089/heq.2019.0102.

\section{Abbreviations Used}

$\mathrm{ADA}=$ American Diabetes Association

$\mathrm{BMI}=$ body mass index

$\mathrm{CHIS}=$ California Health Interview Survey

$\mathrm{DM}=$ diabetes mellitus

DMSE $=$ DM self-management education

FAITH-DM $=$ Feeding America Intervention Trial for Health-Diabetes Mellitus

$\mathrm{FI}=$ food insecurity

$\mathrm{HbA} 1 \mathrm{c}=$ hemoglobin $\mathrm{A} 1 \mathrm{c}$

PHQ-8 = Patient Health Questionnaire-8

$\mathrm{POC}=$ point of care

$\mathrm{SE}=$ standard error

SSBs $=$ sugar-sweetened beverages

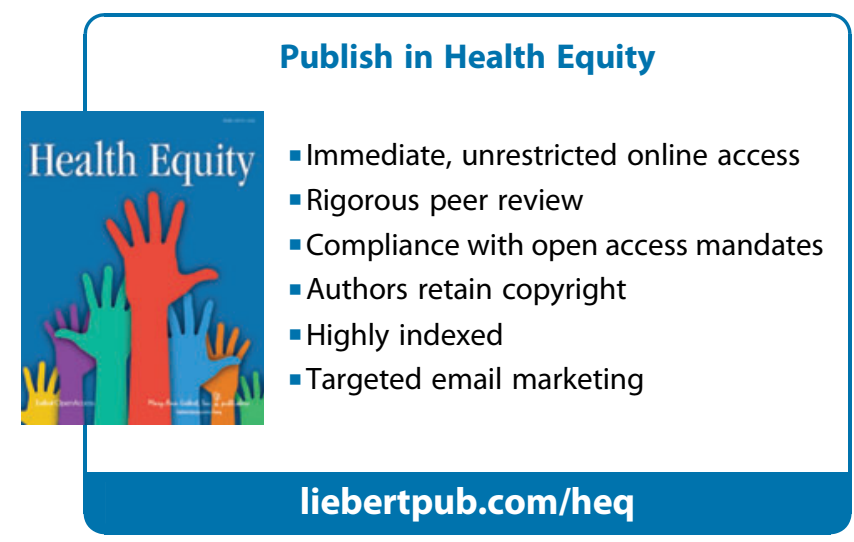

